\title{
DETECCION DE ANTICUERPOS ANTIPLASMODIUM POR ELISA EN DONANTES DE SANGRE
}

\author{
PATRICIA OLAYA DE MORALES, * CARLOS A. ESPINAL T. **
}

\begin{abstract}
La malaria, una enfermedad transmitida por mosquitos del género anopheles, puede ser inducida a través de transfusiones de sangre infectada con alguna de las especies de Plasmodium que afectan al hombre.
\end{abstract}

Con el objeto de determinar el riesgo potencial de infección inducida por transfusiones, se analizaron durante 9 meses y mediante la técnica de E.L.I.S.A., las muestras de suero tomadas a los donantes de sangre del Hospital Militar Central de Bogotá. El 8,6 por mil de las 3114 muestras analizadas, resultaron positivas para anticuerpos antimaláricos y durante el tiempo del estudio fueron detectados 3 casos de malaria inducida por transfusiones.

La malaria, transmitida normalmente por la picadura de mosquitos del género Anopheles, puede ser inducida también por la transfusión de sangre de donantes afectados por la enfermedad. Estos donantes se caracterizan por desarrollar infecciones crónicas y subclínicas, cuyo bajo recuento de parásitos es difícilmente detectable mediante el examen microscópico de sangre periférica $(1,23)$.

Gerhardt en 1884 (4) fue el primero en demostrar esta vía de infección al inocular sangre de un paciente infectado a dos individuos sanos, con reproducción de la enfermedad. Woosley en 1911 (4), describió en los Estados Unidos el primer caso de malaria post-transfusional en un paciente con anemia perniciosa, quien desarrolló una infección por $P$. vivax 11 días después de recibir sangre de un donante sin antecedentes conocidos de malaria. Desde entonces se han informado casos aislados en pacientes bajo diferentes circunstancias hospitalarias
$(1,4,5,6,7,8)$, sin existir un estudio detallado sobre los donantes de sangre en hospitales localizados cerca o en las áreas maláricas.

La inducción accidental de la enfermedad no solo se presenta con la transfusión de sangre total, sino que puede hacerse también a través de concentrados de leucocitos (9) o de plaquetas (10). Debe siempre tenerse en cuenta que una infección malárica inducida por transfusión puede resultar fatal en pacientes con ciertas enfermedades de base que comprometan el sistema inmune, o en pacientes politraumatizados de alta cirugía, donde la respuesta normal a las infecciones puede estar disminuída.

La detección de anticuerpos antimaláricos en el suero de los donantes de sangre podría representar el mejor método de control y prevención de la malaria post-transfusional, al no utilizar las unidades de sangre positivas en los pacientes hospitalizados.

\footnotetext{
* Microbióloga, Unidad de Inmunología de Malaria, Grupo de Microbiología e Inmunología, Instituto Nacional de Salud (INS). Apartado Aéreo 80334, Bogotá, Colombia, S.A.

** Médico, Jefe de la Unidad de Inmunología de Malaria, Instituto Nacional de Salud.
} 
El método de E.L.I.S.A. (Enzyme Linked Immunosorbent Assay), y la Inmunofluorescencia indirecta, son las técnicas más utilizadas en el diagnóstico seroepidemiológico de la malaria, $(11,12)$; sin embargo, su aplicación rutinaria en el campo ha tenido algunas dificultades, especialmente en la obtención de los antígenos necesarios para realizar cualquiera de los dos métodos mencionados. Debe recordarse además que la presencia de los anticuerpos antimaláricos en el suero de los donantes no necesariamente significa infección activa, interpretándose siempre los resultados positivos como el riesgo intra-hospitalario de contraer la infección post-transfusional.

El presente trabajo pretende analizar el riesgo hospitalario de la infección malárica inducida por transfusión sanguínea, mediante la detección de anticuerpos por la técnica de E.L.I.S.A. en los donantes de sangre del Hospital Militar Central (H.M.C.), de Bogotá.

\section{MATERIALES Y METODOS}

El Hospital Militar Central (HMC) fue seleccionado para el estudio debido a que está localizado en un área no malárica donde se recibe un número alto de pacientes con diversos tipos de patología, presumiblemente sin ninguna inmunidad contra la infección malárica. El grupo de donantes de sangre está constituído principalmente por personal de las fuerzas militares. Recibe además el Hospital un número apreciable de casos de malaria debido a su relativa cercanía a áreas endémicas y a la transferencia de pacientes en servicio militar activo, provenientes de las principales zonas de alta transmisión en el país.

\section{Sueros}

Durante un período de 9 meses, comprendido entre el $1^{\circ}$ de enero y el 31 de agosto de 1980 , se tomaron muestras de sangre a todos los donantes. Una vez separados los sueros se congelaron a $-70^{\circ} \mathrm{C}$ hasta su procesamiento final.

El valor negativo para la técnica se obtuvo de 88 sueros de individuos en un rango de edad entre los 18 a los 25 años, sin ningún antecedente de malaria $o$ de residencia temporal en zonas maláricas.

\section{Antígeno}

El antígeno soluble se preparó a partir de la cepa de $P$. falciparum FCR-3, cedida por el Dr. W. Trager. La cepa se mantuvo en cultivo continuo siguiendo el método de Jensen y Trager (13). Los parásitos se procesaron cuando aproximadamente un $60 \%$ de las formas eran esquizontes, congelándose a $-70^{\circ} \mathrm{C}$ luego de varios lavados en solución salina con $\mathrm{pH}$ de 7,2 . Después de descongelación a temperatura ambiente, los parásitos fueron fraccionados con un sonicador Biosonic II, a fuerza 40 durante 30 segundos y posteriormente centrifugados a $8.500 \mathrm{rpm}$ durante 30 minutos. El sobrenadante con el antígeno soluble fue congelado en tubos capilares a $-70^{\circ} \mathrm{C}$ hasta su utilización. La dilución óptima del antígeno de $1: 800$, fue determinada con sueros positivos de pacientes infectados con $P$. falciparum y sueros negativos de individuos sin antecedentes de malaria (Cuadro No. 1, Fig. No. 1).

\section{Conjugado y Substrato}

El conjugado utilizado fue la fosfatasa alcalina comercial conjugada con Anti-IgG humana producida en cabra (Miles Yeda). La dilución 1:800 del conjugado se obtuvo al predosificar los orificios de las microplacas de titulación (Dynatech Lab. Inc) con 200 microlitros de IgG humana a una concentración de $125 \mathrm{ng} / \mathrm{ml}$, aislada y purificada en la unidad de inmunoquímica del Instituto Nacional de Salud (Cuadro No. 2, Fig. No. 2).

CUADRO №

TITULACION DEL ANTIGENO FCR-3 CON EL SUERO POSITIVO $B^{*}$

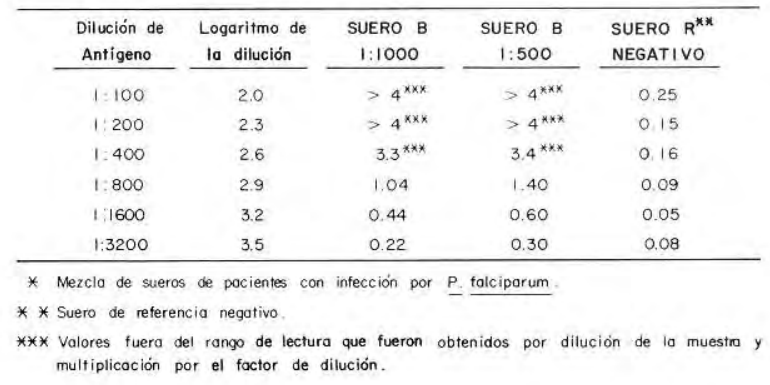


Posteriormente esta dilución fue confirmada utilizando el antígeno y los sueros de referencia positivos y negativos.

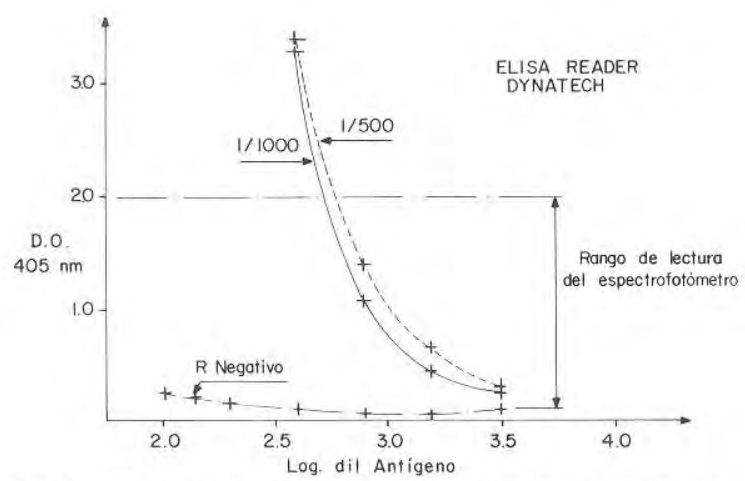

Fig. № I Titulación del Antigeno FCR-3, con Sueros de Referencia positivos y

CUADRO № 2

VALORES EN LA TITULACION DEL CONJUGADO*

\begin{tabular}{|c|c|c|}
\hline $\begin{array}{l}\text { Dilución de } \\
\text { Conjugado }\end{array}$ & $\begin{array}{l}\text { Logaritmo de } \\
\text { la dilución }\end{array}$ & $\begin{array}{l}\text { Lecfura } \\
\text { D.O.** }\end{array}$ \\
\hline $1: 100$ & 2.0 & $>4^{* * *}$ \\
\hline $1: 200$ & 2.3 & $2.96^{* * *}$ \\
\hline 1.400 & 2.6 & 2.00 \\
\hline $1: 800$ & 2.9 & 1.04 \\
\hline $1: 1600$ & 3.2 & 0.42 \\
\hline $1: 3200$ & 3.5 & 0.20 \\
\hline
\end{tabular}

* Fosfatasa alcalina-Anti-lgG humana

** Valores de densidad óptica.

*** Valores fuera del rango de lectura que fueron obtenidos por dilución de la muestra y multiplicación por el factor de dilución.

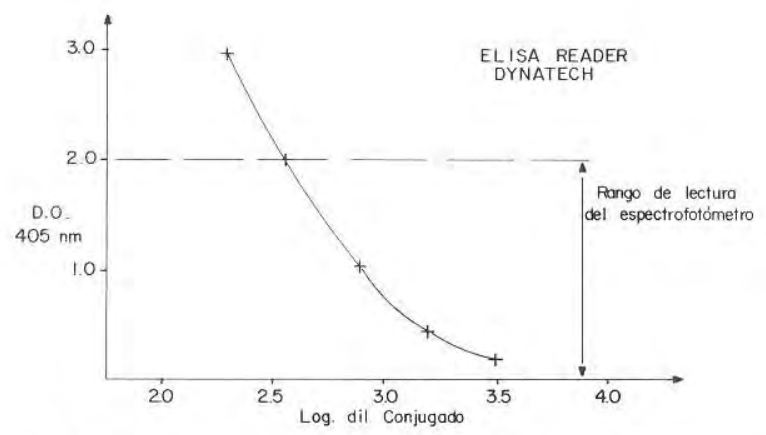

Fig № 2 Titulación del Conjugado con $125 \mathrm{ng} / \mathrm{ml}$ de $\operatorname{lgg}$ humana
El substrato empleado fue P-Nitrofenil fosfato (Sigma 104) a una concentración de $1 \mathrm{mg} / \mathrm{ml}$ en una solución tampón de dietanolamina y con un $\mathrm{pH}$ de 9,8 .

Procedimiento de la técnica de E.L.I.S.A.

El método empleado en el estudio fue el desarrollado por Voller y col (12). Los orificios de las placas de microtitulación se llenaron con 200 microlitros del antígeno diluído 1:800, en una solución tampón de carbonato $0,05 \mathrm{M}, \mathrm{pH} 9,6$; las microplacas se incubaron a temperatura ambiente por 2 horas. La solución de antígeno se removió y las microplacas se lavaron en 3 ocasiones con una solución fosfato-salina $0,15 \mathrm{M}, \mathrm{pH}$ 7,4, con $0,05 \%$ de Tween 20 (PBS/T).

Posteriormente se colocaron 200 microlitros de los sueros diluidos 1:500 en $\mathrm{PBS} / \mathrm{T}$, en los orificios de las microplacas, incubándolas a temperatura ambiente durante 2 horas. Después de un lavado semejante al anterior, se adicionaron 200 microlitros de conjugado diluído 1:800 en $\mathrm{PBS} / \mathrm{T}$, y se incubaron a $4^{\circ} \mathrm{C}$ durante la noche. Al siguiente día, después de un nuevo lavado, se agregó a cada orificio 200 microlitros del substrato, el cual se dejó reaccionar durante 30 minutos, deteniendo la reacción enzimática mediante la adición de 50 microlitros de $\mathrm{NaOH}, 1 \mathrm{~N}$.

La densidad óptica a 405nm (E 405) se determinó en un E.L.I.S.A. Reader (Dynatech). Un valor igual o mayor a 0,2 fue considerado como positivo. Todos los sueros se probaron por duplicado y se utilizó para cada suero el promedio de su densidad óptica.

\section{RESULTADOS}

\section{Sueros controles y valor negativo}

Ninguno de los 88 sueros de individuos residentes en Bogotá tuvo un valor $\geq .0,2$. La distribución de frecuencias en valores de densidad óptica menores de 0,10 se encontró en 71 muestras; entre $0,11-0,15$ en 12 muestras y de $0,16-0,19$ en 5 sueros, para E.L.I.S.A., utilizando antígeno de $P$. falciparum. El valor promedio obtenido fue 
de 0,07 con una desviación estandar de 0,04, la que sumada 3 veces al promedio, determinó el valor de 0,2 como límite entre positivo y negativo.

Sueros de los donantes del

Banco de Sangre (HMC)

Un total de 3.114 muestras se colectaron durante los 9 meses del estudio. El 90.55\% de los donantes eran del sexo masculino y el $85,3 \%$ tenían edades entre los 15 y los 25 años, debido a que en su gran mayoría la fuente de donantes está representada por población militar.

La frecuencia de grupos sanguíneos y factor Rh en la población de donantes fue de $57,83 \%$ para el 0 , Rh positivo; $27,81 \%$ para el A, Rh positivo y $6,84 \%$ para el $B, R h$ positivo, como grupos predominantes $y$ refleja la prevalencia en la población general (14).

Un total de 27 sueros, el 8,6 por mil de las 3.114 muestras analizadas, resultaron positivas para anticuerpos antimaláricos utilizando antígenos de $P$. falciparum. El Cuadro No. 3 muestra la frecuencia de los valores absolutos en estos sueros positivos, y en el Cuadro No. 4 están representados los valores absolutos de los sueros negativos.

Tres casos de malaria inducida por transfusiones se detectaron durante el tiempo del estudio. El primero de ellos tuvo una infección por P. vivaxy los dos restantes se infectaron con glóbulos rojos parasitados por $P$. falciparum provenientes del mismo donante.

CUADRO № 3

SUEROS POSITIVOS PARA ELISA. EN DONANTES DE SANGRE H.M.C.

\begin{tabular}{ccc}
\hline $\begin{array}{c}\text { Valores de ELISA } \\
\text { Densidad Optica }\end{array}$ & & $\begin{array}{c}\text { № de } \\
\text { Sueros }\end{array}$ \\
$0.20-0.30$ & & 14 \\
$0.31-0.40$ & 6 \\
$0.41-0.50$ & 3 \\
$\geq 0.51$ & 4 \\
\hline TOTAL & 27 \\
\hline
\end{tabular}

CUADRO № 4

SUEROS NEGATIVOS PARA ELISA EN DONANTES DE SANGRE

H.M.C.

\begin{tabular}{ccc}
\hline $\begin{array}{c}\text { Valores de ELISA } \\
\text { Densidad Optica }\end{array}$ & & $\begin{array}{c}\text { No de } \\
\text { Sueros }\end{array}$ \\
$\begin{array}{c}\text { Se.10 } \\
0.11-0.15\end{array}$ & 2.465 \\
$0.16-0.19$ & 457 \\
\hline TOTAL & 165 \\
\hline
\end{tabular}

\section{DISCUSION}

Los estudios serológicos para la detección de anticuerpos antimaláricos en los donantes de sangre han sido siempre realizados después de presentarse un casơ clínico de malaria inducida por transfusión (15). Estos estudios efectuados con la técnica de anticuerpos fluorescentes revelan la presencia de anticuerpos antimaláricos que confirman los antecedentes bien sea de enfermedad o de residencia en áreas endémicas.

Las infecciones crónicas y con bajo recuento de parásitos por microlitro de sangre, no demostrables incluso al examen de gota gruesa, son frecuentes en pacientes con $P$. vivax y $P$. malariae debido a las condiciones biológicas especiales de ambas especies de parásitos (16). No es este el caso con el P. falciparum, donde lo más común son infecciones agudas o crónicas de escasa duración, las cuales en su mayoría son todavía sintomáticas, requiriendo tratamiento inmediato.

El problema para los bancos de sangre lo presentan los portadores asintomáticos de la malaria, los cuales pueden llevar en sus glóbulos rojos cualquiera de las especies de Plasmodium, convirtiéndose en un riesgo potencial de infección cuando sirven como 
donantes de sangre. Bajo estas condiciones descritas y en el caso particular del $P$. falciparum, debe existir una relación especial huesped-parásito para su persistencia prolongada y asintomática en el individuo, ya que la inducción de una sólida inmunidad solo se presenta con infecciones repetidas al residir por largo tiempo en las regiones endémicas. En algunas de las historias de donantes cuya sangre ha infectado al receptor, no hay indicios claros de infección previa y únicamente permanecieron en el área malárica durante un año aproximadamente (17).

Nuestro primer caso de malaria posttransfusional en el HMC se presentó durante la colección de sueros para el estudio. El receptor, un paciente de 40 años recibió una transfusión de sangre durante una cirugía de tórax y al cabo de 7 días, desarrolló una infección por $P$. vivax, que fue tratada en el hospital. Una de las unidades de sangre analizadas posteriormente por la técnica de E.L.I.S.A. resultó positiva para anticuerpos antimaláricos, con un valor en D.O. de 0,25. El donante no pudo ser localizado para estudio y tratamiento adecuados.

Otros dos casos, ocurridos durante la fase de análisis de este trabajo, se infectaron a partir de un mismo donante. El primero recibió glóbulos rojos y el segundo fue transfundido con plasma rico en plaquetas. Ambos pacientes desarrollaron en corto tiempo una infección aguda por $P$. falciparum y fueron tratados adecuadamente por el servicio médico del hospital. El donante, localizado dos meses mas tarde y completamente asintomático, fue seguido en nuestro laboratorio mediante el examen de gota gruesa seriada, encontrándose, lo que es poco usual en estos casos, un solo anillo en una de las muestras.

El control de las infecciones maláricas inducidas por transfusiones sanguíneas se ha basado tradicionalmente en el interrogatorio de los donantes en relación con sus antecedentes de infección o residencia en áreas maláricas; sin embargo, los datos obtenidos son de poca confiabilidad. El examen de gota gruesa en los donantes sospechosos tampoco es representativo, ya que las parasitemias no son en general detectables en sangre periférica. Otras medidas, como la adición de drogas antimaláricas a las unidades de recolección son poco prácticas debido al alto número de donantes y a la resistencia del P. falciparum a algunos de los compuestos más ampliamente utilizados. Con esta base, la serología, sumada a un interrogatorio consciente, viene a representar la medida más adecuada en el estudio y control de esta infección intrahospitalaria. La aplicación práctica debe realizarse lógicamente, en hospitales localizados en las cercaníaz de las áreas maláricas a donde tengan acceso individuos residentes en las regiones endémicas, además del flujo normal de pacientes con diversos tipos de patología y sin experiencia previa con el Plasmodium.

El E.L.I.S.A., técnica de alta sensibilidad, bajo costo y lectura objetiva, ha sido uno de los métodos inmunoenzimáticos más difundidos para el estudio de las enfermedades infecciosas. En nuestro caso, la detección de anticuerpos antimaláricos en el 8,6 por mil de las muestras analizadas, representa un alto riesgo de infección intrahospitalaria por malaria ya que en las áreas no endémicas, un individuo con anticuerpos antimaláricos debe considerarse como un portador potencial y debe descartarse como donante.

El trabajo realizado en el HMC representa el primer estudio prospectivo en donantes de sangre utilizando la técnica de E.L.I.S.A. Los informes sobre malaria por transfusiones están basados en casos clínicos: en México, estudios realizados por Sánchez-Medal mostraron una incidencia de 0,13 casos por mil unidades de sangre entre 1967-1970, y de 3,0 entre 1968-1969 (4); en Rumania ha sido de 0,7 casos por mil en 5 años y en las Filipinas de 0,45 por mil en 6 años (4).

El método de E.L.I.S.A. se llevó a cabo en forma semicuantitativa, determinando los valores de D.O en un espectrofotómetro; sin embargo, puede hacerse únicamente en forma cualitativa, ya que ante la presencia de anticuerpos en los sueros analizados se presenta una reacción de color la cual será comparada con los patrones positivos y negativos, confirmando la infección presente 
PATRICIA OLAYA DE MORALES, CARLOS A. ESPINAL T.

o pasada de malaria. El establecimiento rutinario de la técnica de E.L.I.S.A. en los bancos de sangre de hospitales con las características antes mencionadas, es una consideración que debe tenerse en cuenta para el control de la malaria post-transfusional, debido a que las consecuencias de la infección en pacientes quirúrgicos inmunosuprimidos o bajo otras condiciones, pueden ser funestas.

\section{SUMMARY}

In order to determine the risk of transfusion-induced malaria in the Blood Bank of the Hospital Militar Central in Bogotá, 3114 sera from blood donnors were collected during a period of nine months. These sera were analysed by the indirect E.L.I.S.A. technique using $P$. falciparum antigen containing more than $60 \%$ of schizonts. Malaria antibodies were detected in 27 sera, representing 8.6 per thousand of total samples. Three cases of malaria following blood transfusion were recorded during the study.

\section{AGRADECIMIENTOS}

Los autores expresan sus agradecimientos a las Bacteriólogas Blanca Joya e Inés de Santodomingo, del Banco de Sangre del Hospital Militar Central y al Doctor Hernán Torres I, Jefe de Medicina Interna, por su valiosa y decidida colaboración.

\section{BIBLIOGRAFIA}

1. Choinacki R E, Brazinsky J H, Barret O Jr, Transfusión introduced falciparum malaria. The New Eng J. Med $1968 ; 279,(18): 984$

2. Grant D B, Perinpanayagam M S, Shute P G, Zeitlin R A. A Case of malignant tertian (Plasmodium falciparum) malaria after blood transfusion. Lancet 1960, 2: 469
3. Verdrager J. Cerebral malaria following blood transfu sion. J. Trop. Med. Hyg. 1969, 72, 131.

4. Bruce Chwatt L J. Blood transfusion and tropical disease. Trop. Dis. Bull. 1972; 69 (9): 825

5. Black R H. Investigation of blood donnors in accidental transfusion malaria Plasmodium vivax, falciparum and malariae infections. Trop. Med. Dis. Bull. 1961; 58 (3): 289.

6. Peña Chavarria $A$, Vasquez Vigo M. Paludismo inducido. Bol. Of. San. Panam. 1961,50, (2), 131

7. Oluwolf G, Aiao. Malaria and postoperative fever. J. Trop. Med. Hyg. 1978; 81 (8) 153

8. Vargas L. Notas sobre la trnasfusión sanguinea y el paludismo inducido en México. Salud Pública de México. 1972: $14(13): 353$

9. Dover A S, Guinee $V$ F. Malaria transmision by leukocite component therapy J.A.M.A. 1971, 217, (2): 1701.

10. Garfield M D, Ershler W B, Maki D G. Malaria transmission by platelet concentrate transfusion. J.A.M.A. 1978, 240 (21): 2285

11. Collins W, Warren MCW, Skinner J C, Fredericks $H$ J. Studies on the relationship between fluorescent antibody response and ecology of malaria in Malaysia. Bull. W. H. o. $1969,39: 451$.

12. Voller A y col. New serological test for malaria antibodies. British M.J. 1975, 1: 659

13. Jensen J B Trager W. Plasmodium falciparum in culture. Establishment of additional strains. Am. J. Trop. Med. Hyg. 1978,27 (4): 746

14. Evidencia clínica. Investigación Nacional de Morbilidad. Ministerio de Salud Pública. Ascofame 1969: 55.

15. Sulzer $A$, Wilson $M$. The indirect fluorescent antibody test for the detection of ocult malaria in blood donnors. Bull. WId. Hith. Org. 1972, 45: 375 .

16. Corradeti A. Relapses and delayed primary attacks in malaria. Trans. Roy. Soc. Trop. Med. Hyg. 1982, 76: 279.

17. Fisher $G U$. Schultz M. Unusual host parasite relationship in blood donnors responsible for transfusion induced falciparum malaria. Lancet 1969. 2: 716. 